\title{
Comparative efficacy of continuous infusion of bupivacaine/fentanyl and ropivacaine/fentanyl for paediatric pain control after the Ravitch procedure and thoracotomy. A prospective randomized study
}

\author{
Lucyna Tomaszek, Dariusz Fenikowski, Danuta Gawron, Halina Komotajtys
}

\begin{abstract}
Aims. (1) To compare the efficacy of bupivacaine/fentanyl and ropivacaine/fentanyl for postoperative pain control (2). To identify the predictors of acute post-operative pain at rest, during deep breathing and coughing.

Methods. The study was performed in patients aged 6-18 years after thoracic surgery. The subjects were randomized to the bupivacaine $0.125 \% /$ fentanyl $5.0 \mu \mathrm{g} / \mathrm{mL}(\mathrm{n}=46)$ or ropivacaine $0.2 \% /$ fentanyl $5.0 \mu \mathrm{g} / \mathrm{mL}$ ( $\mathrm{n}=48$ ) group; analgesic mixtures were administered through epidural catheter. All the patients received paracetamol and non-steroidal antiinflammatory drugs. The observation period after surgery lasted $72 \mathrm{~h}$. Pain intensity was assessed at rest, during deep breathing and coughing and was based on the Numerical Rating Scale and the FLACC scale (range 0-10). If the pain was above $2 / 10$, the analgesia was modified.

Results. Median pain scores at rest (0.4 vs. 0.5$)$, during deep breathing (0.3 vs. 0.3$)$ and coughing (0.6 vs. 0.6$)$ were comparable in BF and RF group. The intensity of pain at rest was associated with the number of drains inserted into the thorax $(\beta=0.39)$, the number of pain intensity measurements $(\beta=0.36)$ and the number of nursing interventions undertaken to relieve pain $(\beta=0.16)$. Pain intensity at rest determined the intensity of pain during deep breathing $(\beta=0.60)$, which in turn decided on the severity of pain during coughing $(\beta=0.80)$. The intensity of pain was increased by age.

Conclusions. Thoracic epidural bupivacaine/fentanyl provided adequate pain relief and similar analgesia to ropivacaine/fentanyl. The effectiveness of analgesia depended on the number of pain measurements and interventions by nurses to relieve the pain.

Trial Registration: ClinicalTrials.gov; Multimodal Analgesia in Children and Adolescents After the Ravitch Procedure and Thoracotomy; NCT03444636; https://clinicaltrials.gov/ct2/show/NCT03444636
\end{abstract}

Key words: postoperative pain, Ravitch procedure, thoracotomy, adolescent, child, multimodal analgesia, thoracic epidural catheter

Received: August 18, 2018; Accepted: November 5, 2018; Available online: November 16, 2018 https://doi.org/10.5507/bp.2018.072

(c) 2019 The Authors. This is an open access article licensed under the Creative Commons Attribution License (https://creativecommons.org/licenses/by/4.0/).

Department of Thoracic Surgery, Institute for Tuberculosis and Lung Diseases, Pediatric Division, Rabka-Zdroj, Poland Corresponding author: Lucyna Tomaszek, e-mail: Itomaszek@igrabka.edu.pl

\section{INTRODUCTION}

The modified Ravitch surgery is one of the techniques used to treat the deformity of the anterior wall of the chest $^{1}$. Surgical treatment in diseases of the lungs, pleural cavity, mediastinum and diaphragm is thoracotomy ${ }^{2,3}$. Due to extensive tissue injury and the consequent severe postoperative pain ${ }^{3,4}$ thoracic surgery requires effective analgesia. The authors of the Polish paediatric guidelines on postoperative pain with a predicted intensity $>7 / 10$ on the numerical rating scale (NRS) and a duration longer than 3 days, the criteria met by thoracic surgeries, recommend multimodal analgesia ${ }^{5}$.

The multimodal pain management concept involves influencing multiple levels of pain induction and its processing (peripheral action, spinal cord). For this purpose, the combinations of local anaesthetics, opioids and nonopioid analgesics (paracetamol, metamizol, non-steroidal anti-inflammatory drugs) are used ${ }^{5-7}$.

Analgesic mixtures containing bupivacaine and fen- tanyl or ropivacaine and fentanyl administered through a thoracic epidural catheter (TEC) are effective in relieving pain after thoracic surgery ${ }^{8-10}$. However, bupivacaine is much cheaper than ropivacaine ${ }^{11}$.

The intensity of pain experienced by the patient after surgery is a measure of the effectiveness of analgesia. The efficacy of analgesia is determined not only by the right analgesic ordered by the doctor in the appropriate dose ${ }^{7}$, but also by the route of drug administration ${ }^{12}$, the assessment of pain intensity by the nurse ${ }^{13}$ and whether nurses have the opportunity to adjust analgesic treatment in the scope of the doctor's order ${ }^{12}$. Identifying factors that determine the effectiveness of analgesia can help to optimize the quality of patient care in terms of postoperative pain and to prevent clinical, psychological, and socioeconomic adverse consequences of insufficient pain relief. It is well documented that inadequate pain control may delay recovery, increase morbidity and mortality, increase anxiety, decrease patient satisfaction, and lead to chronic persistent postsurgical pain ${ }^{14,15}$. Unfortunately, results of many 
Table 1. Demographic and clinical data of patients.

\begin{tabular}{|c|c|c|c|c|c|}
\hline \multirow{2}{*}{$\begin{array}{l}\text { Parameter } \\
\text { Age (years) }\end{array}$} & & \multirow{2}{*}{$\frac{\text { Group BF }(n=46)}{14(10-15)}$} & \multirow{2}{*}{$\frac{\text { Group RF }(n=48)}{13(9-15)}$} & \multicolumn{2}{|c|}{$P$} \\
\hline & & & & $\mathrm{Z}=0.718$ & 0.472 \\
\hline \multicolumn{2}{|c|}{ Body height $(\mathrm{cm})$} & $167(144-175)$ & $163(129-173)$ & $Z=0.593$ & 0.552 \\
\hline \multicolumn{2}{|l|}{ Body weight (kg) } & $51(40-54)$ & $49(26-58)$ & $\mathrm{Z}=0.272$ & 0.785 \\
\hline \multicolumn{2}{|l|}{$\operatorname{BMI}\left(\mathrm{kg} / \mathrm{m}^{2}\right)$} & $19(17-19)$ & $17(15-20)$ & $Z=0.805$ & 0.420 \\
\hline \multicolumn{2}{|c|}{ Duration of anaesthesia (min) } & $200(170-225)$ & $187(160-217)$ & $\mathrm{Z}=1.418$ & 0.156 \\
\hline \multicolumn{2}{|c|}{ Duration of surgery (min) } & $130(150-165)$ & $130(102-147)$ & $Z=0.544$ & 0.585 \\
\hline \multicolumn{2}{|c|}{ Duration of epidural analgesia (h) } & $70(50-90)$ & $73.0(65-97)$ & $Z=-1.682$ & 0.092 \\
\hline \multirow[t]{2}{*}{ Sex (\%) } & Girls & $13(28.3 \%)$ & $13(27.1 \%)$ & $\chi^{2}=0.016$ & 0.898 \\
\hline & Boys & $33(71.7 \%)$ & $35(72.9 \%)$ & & \\
\hline \multirow[t]{3}{*}{ ASA (\%) } & 1 & $38(82.6 \%)$ & $42(87.5 \%)$ & $\chi^{2}=0.560$ & 0.755 \\
\hline & 2 & $6(13.0 \%)$ & $4(8.3 \%)$ & & \\
\hline & 3 & $2(4.3 \%)$ & $2(4.2 \%)$ & & \\
\hline \multirow[t]{2}{*}{ Type of surgery } & Ravitch & $32(69.6 \%)$ & $26(54.2 \%)$ & $\chi^{2}=2.356$ & 0.124 \\
\hline & Thoracotomy & $14(30.4 \%)$ & $22(45.8 \%)$ & & \\
\hline \multirow[t]{2}{*}{ Drain } & One & $40(87.0 \%)$ & $44(91.7 \%)$ & $\chi^{2}=0.548$ & 0.518 \\
\hline & Two* & $6(13.0 \%)$ & $4(8.3 \%)$ & & \\
\hline
\end{tabular}

Results presented as medians (upper and lower quartile) or numbers (percentages); ASA - American Society of Anaesthesiologists; BF - epidural infusion of bupivacaine $0.125 \%$ with fentanyl $5 \mu \mathrm{g} / \mathrm{mL}$; RF - epidural infusion of ropivacaine $0.2 \%$ with fentanyl $5 \mu \mathrm{g} / \mathrm{mL}$

* Two drains in the pleural cavity had $10(10.6 \%)$ patients after thoracotomy, $8(30.8 \%)$ girls and $2(2.9 \%)$ boys.

studies conducted in different countries show that the treatment of postoperative pain in children is inadequate - too many children still experience intense pain ${ }^{16-21}$.

The aim of the study was (1) to evaluate the efficacy of pain control provided by the multimodal approach that involved continuous bupivacaine/fentanyl vs. ropivacaine/ fentanyl infusion through thoracic epidural catheters in children and adolescent after Ravitch surgery and thoracotomy; (2) to identify the predictors of acute post-operative pain at rest, during deep breathing and coughing.

\section{METHODS}

\section{Trial design, participants}

The prospective randomized study was conducted in the Department of Thoracic Surgery of the Institute of Tuberculosis and Lung Diseases in Rabka Zdrój, between March 2015 and December 2016, in the group of 94 subjects aged 6-18 years.

The study was designed as an interventional randomized controlled trial with 1:1 parallel assignment to the intervention and control arms. No important changes were made to the methods after the trial began.

The following patients were qualified: aged 5-18 years; of both sexes; after obtaining the informed written consent of both patients (from the age of 16) and their legal guardians; those who were qualified for the correction of the anterior thoracic wall by the Ravitch modified method or for thoracotomy through the lateral access in diseases of the lungs, pleural cavity and mediastinum; those who were planned to receive postoperative epidural analgesia; whose physical condition was determined at the level of I-III according to the American Society of Anaesthesiologists (ASA).
The study excluded the following patients: diagnosed with psychiatric disorders, treated oncologically, experiencing pain before surgery, with impaired verbal communication, and the lack of postoperative chest drainage.

\section{Ethics}

The study was carried out according to the ethical principles of the Helsinki Declaration. Participation in the study was voluntary. The protocol of the study was granted approval by the Local Bioethics Committee at the National Institute of Tuberculosis and Lung Diseases in Warsaw (decision no. KB-2/2015), and written informed consent to participate in the study was sought from legal guardians of all the study subjects. This study was registered in the ClinicalTrials.gov (Identifier: NCT03444636).

\section{Randomization}

The type of postoperative analgesia was a criterion to divide patients into groups. The day before surgery subjects were consecutively enrolled and randomized in strict order as assigned by the allocation sequence to the bupivacaine $0.125 \% /$ fentanyl $(n=46)$ or ropivacaine $0.2 \%$ / fentanyl $(n=48)$ group. $1 \mathrm{~mL}$ of each analgesic solution contained $5 \mu \mathrm{g}$ of fentanyl. The randomized sequence was determined at the beginning of the study and generated by a random number generator (simple randomization). The Participant, Care Provider, Investigator and Outcomes Assessor were not blinded for control or intervention conditions.

\section{General anaesthesia}

To perform the thoracic surgical procedure the patients received general anaesthesia combined with thoracic epidural anaesthesia. All the children were given oral midazolam $(0.2-0.5 \mathrm{mg} / \mathrm{kg})$ as premedication. General 
anaesthesia was induced using fentanyl (1-5 $\mu \mathrm{g} / \mathrm{kg})$ and propofol (3-5 mg/kg). Neuromuscular blockade was obtained with rocuronium $(1 \mathrm{mg} / \mathrm{kg}$ in children $<10$ years old) or pancuronium $(0.1 \mathrm{mg} / \mathrm{kg})$. The anaesthesia was maintained using suprane in an oxygen/air mixture administered through an endotracheal tube. Analgesia was provided with a TEC - after intubation an epidural catheter was placed in the Th4-Th8 intervertebral space by the midline approach and using the loss of resistance technique. On completion of the surgical procedure, tracheal extubation was performed in the operating room and the patients were transferred to the postoperative intensive care unit.

\section{Pain management protocol}

In the operating theatre, before anaesthesia induction - as pre-emptive analgesia - the patients received intravenous paracetamol $(15 \mathrm{mg} / \mathrm{kg}$ ) and non-steroidal anti-inflammatory drugs (children up to 14 years of age rectal ibuprofen: $10 \mathrm{mg} / \mathrm{kg}$ and children above 14 years of age ketoprofen: $1 \mathrm{mg} / \mathrm{kg}$ intravenously).

Immediately after the insertion of epidural catheter, $2 \%$ lidocaine $(2 \mathrm{mg} / \mathrm{kg}$ ) was administered extradurally. Then after $15 \mathrm{~min}$, the patients in the BF group received $0.5 \%$ bupivacaine $(0.5-1 \mathrm{mg} / \mathrm{kg})$ and those in the $\mathrm{RF}$ group $1 \%$ ropivacaine $(1-3 \mathrm{mg} / \mathrm{kg})$. After $60 \mathrm{~min} 0.125 \%$ solution of bupivacaine with fentanyl or $0.2 \%$ ropivacaine solution with fentanyl was infused with a flow rate of 0.1 $\mathrm{mL} / \mathrm{kg} / \mathrm{h}$.

Depending on the allocation to the group, postoperative analgesia was continued either with $0.125 \%$ bupivacaine and fentanyl, or with $0.2 \%$ ropivacaine and fentanyl, based on the concentration and the flow rate described above. In addition, intravenous paracetamol was administered as standard every $6 \mathrm{~h}$ (the maximum of $60 \mathrm{mg} / \mathrm{kg}$ daily) along with non-steroidal anti-inflammatory drugs. In children $>14$ years of age, ketoprofen was injected in a dose of $1 \mathrm{mg} / \mathrm{kg}$ (the maximum of $200 \mathrm{mg}$ daily) and in younger children ibuprofen (orally or rectally, up to 30 $\mathrm{mg} / \mathrm{kg}$ daily) every $8 \mathrm{~h}$.

\section{Pain intensity}

Pain intensity was measured using the Numerical Rating Scale (NRS) in children $\geq 7$ years old and the FLACC scale in younger children ${ }^{22}$. The former tool is self-descriptive, the second is a behavioural scale. In both cases, the scale range includes $0-10$ pts $(0=$ no pain and 10 = worst pain imaginable).

Postoperative pain was assessed using the dynamic three-step method, i.e. at rest, during deep breathing and coughing (Fig. 1). The measurement always started from the assessment of pain intensity at rest. If the patient reported pain at rest, the pain intensity was evaluated in the scale adequate to the patient's age. If the patient did not feel pain, or the pain was rated at 1-2 pts then the patient was asked to take a deep breath in order to re-evaluate the pain intensity. The absence of pain during deep breathing or its intensity at 1-2 points was an indication for pain measurement while coughing. If the patient reported pain after coughing, its intensity was determined in the same way as before ${ }^{23}$.

On the first postoperative day, for the first four hours, the pain was evaluated every hour, then at least every $4 \mathrm{~h}$, and from the second postoperative day at least four times a day. Pain was also assessed 30 min after the administration of an additional analgesic. Because of variability of the number of pain scores recorded for each patient, mean pain scores for each patient were calculated over the 72-h study period at rest, during deep breathing and coughing.

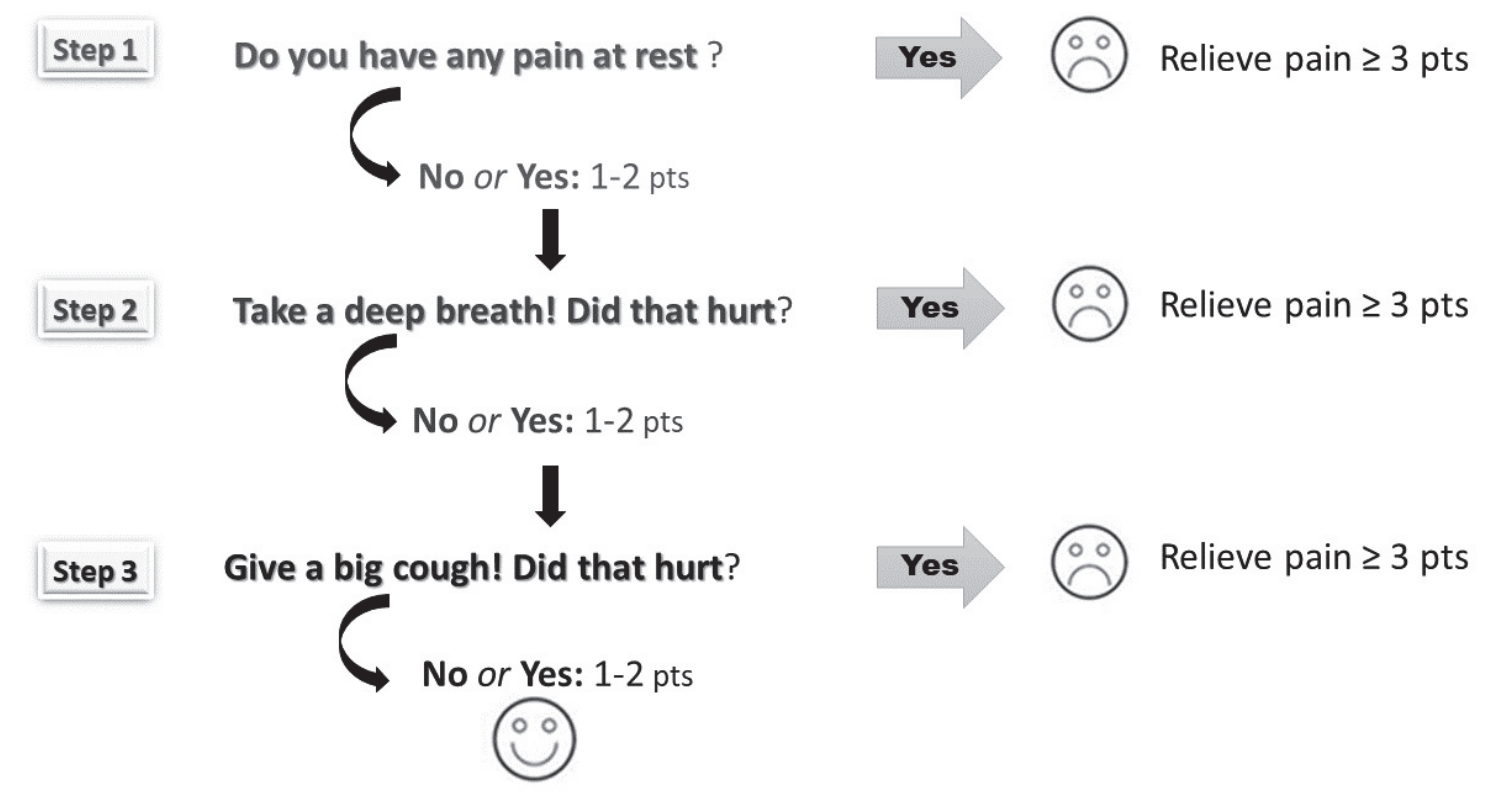

Fig. 1. The three-step pain assessment method (the pain assessment range: $0-10$ pts; the therapeutic goal of pain relief: $0-2$ pts during coughing). 


\section{Modification of analgesia}

If a patient experienced pain $>2$ pts at rest, during deep breathing and coughing, the nurse was obliged to relieve it. This could be done by increasing the flow rate of the analgesic mixture by $10-30 \%$ and/or administration of this mixture in bolus (half-hourly dose) and/or giving metamizol ("rescue drug"; $20 \mathrm{mg} / \mathrm{kg}$; a maximum of $2.5 \mathrm{~g}$ daily). The therapeutic purpose of the analgesic treatment was to obtain $0-2$ pts during coughing.

\section{Patient satisfaction}

After $72 \mathrm{~h}$ of observation, all patients were asked to determine their level of satisfaction. Satisfaction was evaluated on a 4-item scale: analgesia was rated as insufficient, poor, good or very good.

\section{Evaluated parameters and outcomes}

The following variables were recorded: demographic data, ASA, the duration of anaesthesia/surgery/epidural analgesia, type of surgery, drainage, the consumption of drugs administered into the epidural space, the number of nursing interventions undertaken to relive pain $>2 / 10$ pts, the frequency of assessing pain scores, mean pain intensity, maximal pain.

The primary outcome measurements were pain intensity scores between 0 and $72 \mathrm{~h}$ postoperatively. Secondary outcome measures included predictors of pain intensity.

\section{Statistical analysis}

Qualitative variables are expressed as absolute numbers and percentages. Medians (Me), upper and lower quartiles were used as appropriate. The normality of distribution of quantitative variables was tasted by the Shapiro-Wilk test. Differences between the two independent groups were assessed using the Mann-Whitney U test. Cross-group differences between categorical variables were evaluated with the chi' ${ }^{2}$ or exact Fisher test. The correlation between numerical values was determined by the Spearman's rank correlation coefficient (a correlation coefficient below 0.3 was a week correlation, a correlation coefficient between 0.3 and 0.7 a moderate correlation, while a correlation coefficient higher than 0.7 corresponded to a high correlation) (ref. ${ }^{24}$ ).

Multivariable linear regression models were used to find the relation between pain intensity (mean pain within $72 \mathrm{~h}$ of observation) and both demographic (gender, age) and clinical parameters (ASA, duration of surgery, type of surgery, the number of drains inserted into the thorax, the number of pain measurements, the number of nursing interventions). A separate regression model was constructed for pain at rest, pain during deep breathing (pain intensity at rest added as an independent clinical variable) and pain during coughing (pain intensity during deep breathing added as an independent clinical variable). Only independent variables (demographic, clinical) highly and moderately correlated with pain intensity were included in the progressive step-wise regression. Due to the high and moderate correlations between independent variables, the variance inflation factor (VIF) was used to detect multicollinearity in all final regression models (VIF $<1.3$ was assumed as acceptable) (ref..$\left.^{25,26}\right)$. Standardized regression coefficients and 95\% confidence intervals (CI) were calculated for each predictor in model.

Statistical analysis was performed using the tests available in the Statistica 12 program (StatSoft $\AA$, Poland). The level of statistical significance was assumed at $P=0.05$.

\section{Sample size estimation}

The minimal sample size was estimated based on the results of the preliminary study using $\mathrm{t}-$ test. We compared mean pain scores at rest $(\mathrm{M} 1=0.7 ; \mathrm{M} 2=0.4)$, during deep breathing $(\mathrm{M} 1=0.5 ; \mathrm{M} 2=0.2)$ and coughing (M1=0.9; M2=0.6) in $\mathrm{BF}(\mathrm{n}=10)$ and $\mathrm{RF}(\mathrm{n}=10)$ group.

Assuming the same standard deviation for mean pain scores at rest 0.5 and an alpha level of $0.05,45$ patients per group were required to detect significant difference with $80 \%$ power.

In the case of mean pain scores during deep breathing, at least 23 patients in each group were needed to obtain $90 \%$ power of difference detection (assuming alpha of 0.05 and the same $\mathrm{SD}=0.3$ for both groups).

The $80 \%$ power of difference detection in mean pain scores during coughing required at least 45 patients in each group with the assumption of the same standard deviation of 0.5 in both groups and alpha $=0.05$.

\section{RESULTS}

The data from 94 patients were subjected to the final analysis (Fig. 2). The median age of patients was 14 years old. The majority of the subjects were male $(72.3 \%)$ and operated due to deformity of the anterior wall of the chest (61.7\%). Usually, one drain was inserted into the patients' chest - $10(10.6 \%)$ patients after thoracotomy had two drains. The exact demographic and clinical characteristics are shown in Table 1.

\section{The consumption of drugs administered into the epidural space}

Over the whole period of observation, the BF group consumed 237 (149-279) $\mathrm{mL} 0.125 \%$ bupivacaine, while the RF group 220 (150-284) $\mathrm{mL} 0.2 \%$ ropivacaine. Overall, over 72 h, $1185 \mu \mathrm{g}$ (746-1355) vs. $1100 \mu \mathrm{g}$ (7521420) fentanyl were given extradurally in both groups, respectively $(\mathrm{Z}=-0.207 ; P=0.835)$.

\section{Modification of analgesia}

Over the whole period of observation, the nurses modified analgesia 582 times, including 312 times (53.6\%) on the first day, 169 times $(29.0 \%)$ on the second day, and 101 times on the third day (17.3\%). The sum of doses of metamizol as a "rescue drug" was similar in the BF and RF group (Me: 1 [0-2] vs. 1 [0-2], $\mathrm{Z}=-0.593, P=0.552$ ). There was also no difference between BF vs. RF in terms of the total number of interventions (Me: 6 [3-8] vs. 6 [4-7]; $\mathrm{Z}=0.540 ; P=0.588$ ). 


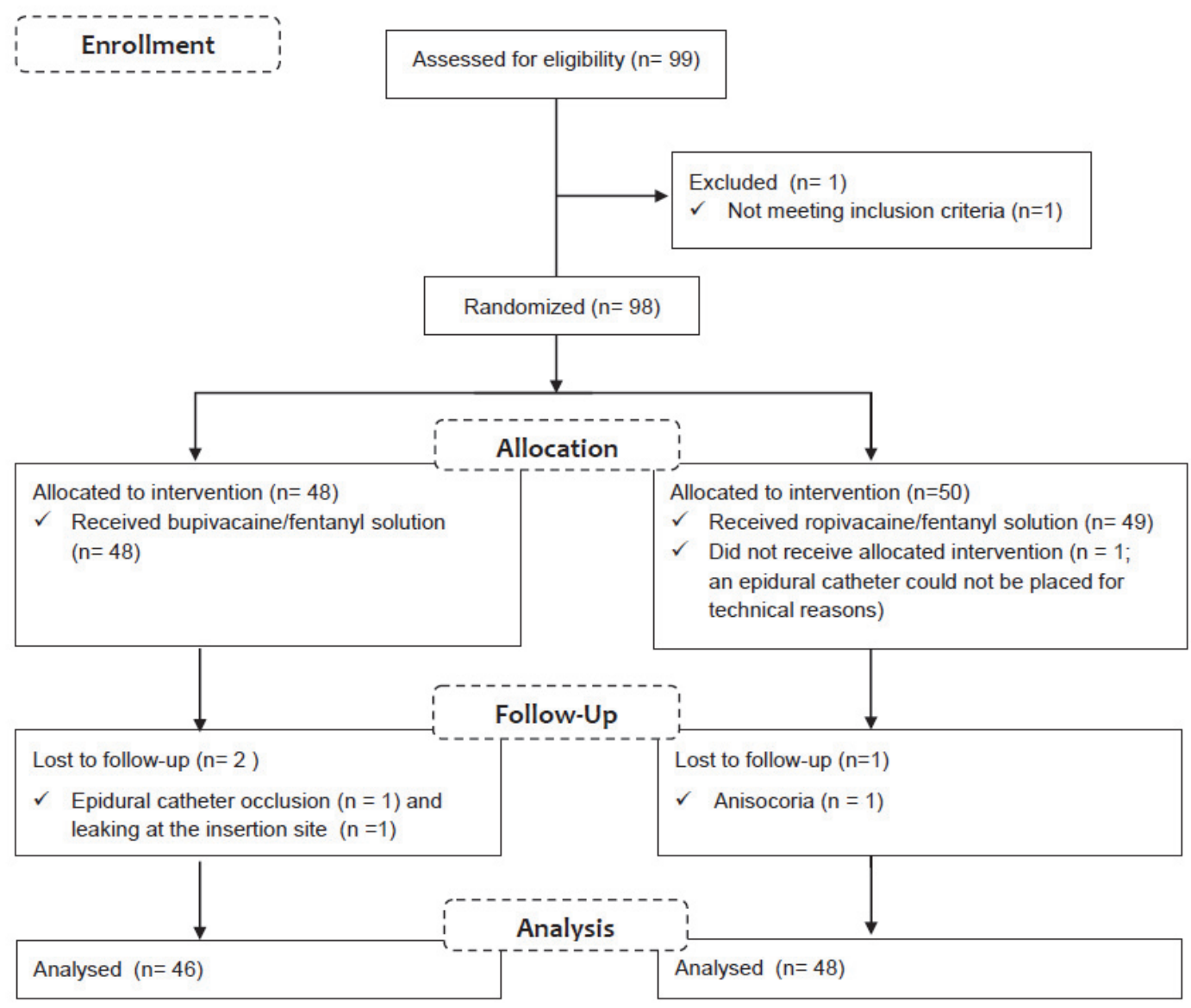

Fig. 2. CONSORT Flow Diagram of patients' enrolment.

\section{The number of pain measurements}

During the entire observation period, the nurses took pain measurements 5947 times, including 2214 (37.2\%) at rest, 1912 (32.1\%) during deep breathing and 1821 (30.6\%) while coughing. There was no significant difference between the BF and the RF group in terms of the number of pain measurements at rest (Me: 22 [20-25] vs. 24 [21-26.5], $\mathrm{Z}=-1.285, P=0.197)$, during deep breathing (Me: 20 [18-22] vs. 20.5 [17.5-22], $Z=-0.239, P=0.810$ ) and coughing (Me: 20 [18-21] vs. 19.5 [17-22], $Z=0.234$, $P=0.813)$.

\section{Pain intensity}

Table 2 provide descriptive statistics for pain intensity (mean, maximal). There was no significant difference between the BF and the RF group in terms of pain intensity at rest, during deep breathing and coughing. The analysis of pain intensity depending on the type of surgical approach and performed at rest showed the significantly higher values of pain intensity in patients treated with thoracotomy than in those subjected to the Ravitch procedure. Significantly more severe pain at rest was recorded in girls than in boys.

\section{Predictors of pain intensity}

Table 3 shows the linear regression models for mean pain intensity at rest, during deep breathing and coughing in patients after thoracic surgery. All presented models are statistically significant $(P<0.01)$. The number of drains inserted into the thorax, the number of pain measurements and the number of nursing interventions were positively associated with pain intensity at rest. Pain intensity at rest and age were positively associated with pain intensity during deep breathing. Pain intensity during breathing and age were positively associated with pain intensity during coughing - this model is very well fitted, and the coefficient of determination is $71 \%$.

\section{Satisfaction with postoperative analgesia}

No significant inter-group difference $(\chi 2=0.570, P$ $=0.450)$ was found in terms of patient satisfaction with postoperative analgesia - $79(84.0 \%)$ patients rated the efficacy of analgesia as very good and 15 (16.0\%) as good.

\section{DISCUSSION}

The results of the study showed that thoracic epidural $0.125 \%$ bupivacaine with $5.0 \mu \mathrm{g} / \mathrm{mL}$ fentanyl provided excellent pain relief and similar analgesia to $0.2 \%$ ropivacaine with $5.0 \mu \mathrm{g} / \mathrm{mL}$ fentanyl in children and adolescent after the Ravitch procedure and thoracotomy. The 
Table 2. Postoperative pain intensity in dynamic conditions (range 0-10 pts).

\begin{tabular}{lllll}
\hline Group & Pain & At rest & During breathing & During coughing \\
\hline BF vs. RF & Mean & $0.4(0.2-0.8)$ vs. & $0.3(0.1-0.6)$ vs. & $0.6(0.3-1.1)$ vs. \\
& & $0.5(0.3-0.8)$ & $0.3(0.1-0.5)$ & $0.6(0.3-1.0)$ \\
Girls vs. Boys & Maximal & $4(3-5)$ vs. $4(3-5)$ & $3(2-3)$ vs. $3(1.5-3.5)$ & $3(2-4)$ vs. $3(2-4)$ \\
& Mean & $0.7(0.3-1.2)$ vs. & $0.4(0.2-0.8)$ vs. & $0.8(0.4-1.4)$ vs. \\
& & $0.4(0.1-0.7)^{*}$ & $0.3(0.1-0.5)$ & $0.6(0.3-1.0)$ \\
Thoracotomy & Maximal & $5(4-6)$ vs. $4(3-5)^{* *}$ & $3(2-4)$ vs. 3 (1.5-3) & $3(2-4)$ vs. 3 (2-4) \\
vs. Ravitch & Mean & $0.6(0.3-1.1)$ vs. & $0.3(0.1-0.6)$ vs. & $0.7(0.3-1.2)$ vs. \\
& Maximal & $0.4(0.1-0.7)^{* * *}$ & $0.3(0.1-0.5)$ & $0.5(0.3-1.1)$ \\
& $5(4-6)$ vs. $4(3-5)^{* * * *}$ & $3(2-3)$ vs. 3 $(2-3)$ & $3(2-4)$ vs. 3 $(2-4)$ \\
\hline
\end{tabular}

Results presented as medians (upper and lower quartile); BF - epidural infusion of bupivacaine $0.125 \%$ with fentanyl $5 \mu \mathrm{g} / \mathrm{mL}$; RF - epidural infusion of ropivacaine $0.2 \%$ with fentanyl $5 \mu \mathrm{g} / \mathrm{mL}$

$* \mathrm{Z}=2.523, P=0.011 ; * * \mathrm{Z}=3.038, P=0.002 ; * * * \mathrm{Z}=2.737 ; P=0.006 ; * * * * \mathrm{Z}=2.453 ; P=0.012$

Table 3. The final models of linear regression by the progressive stepwise method for postoperative pain.

\begin{tabular}{llll}
\hline Pain & Model & Predictors & $\beta(95 \% \mathrm{Cl})$ \\
\hline At rest & $\mathrm{R} 2=0.47 ;$ & The number of drains inserted into the thorax & $0.39(0.23$ to 0.55$)$ \\
& $P<0.001$ & The number of pain measurements & $0.36(0.19$ to 0.53$)$ \\
& & The number of nursing interventions & $0.16(0.001$ to 0.33$)$ \\
During breathing & $\mathrm{R} 2=0.40 ;$ & Pain intensity at rest & $0.60(0.44$ to 0.77$)$ \\
& $P<0.001$ & Age & $0.27(0.10$ to 0.42$)$ \\
During Coughing & $\mathrm{R} 2=0.71 ;$ & Pain intensity during breathing & $0.80(0.68$ to 0.90$)$ \\
& $P<0.01$ & Age & $0.17(0.05$ to 0.28$)$ \\
\hline
\end{tabular}

$\mathrm{R}^{2}$, adjusted determination coefficient; $B$, standardized regression coefficient; $\mathrm{Cl}$, confidence interval

effectiveness of analgesia depends on the number of pain measurements and the number of interventions undertaken by nurses to relieve pain.

In our study the type of analgesic mixture administered to the epidural space did not affect the level of postoperative pain intensity at rest, during deep breathing or coughing. Walaszczyk et al. ${ }^{27}$ found that $0.0625 \%$ epidural bupivacaine has no advantage over $0.1 \%$ epidural ropivacaine for pectus excavatum repair in children. Pain scores requiring intervention ( $>2 / 10$ according to NRS) were recorded with similar frequency in both groups. Macias et al. ${ }^{28}$ reported similar observations in adult patients after a thoracotomy using $0.1 \%$ bupivacaine/fentanyl $5 \mu \mathrm{g} / \mathrm{mL}$ and $0.15 \%$ ropivacaine/fentanyl $5 \mu \mathrm{g} / \mathrm{mL}$.

With the intent of improving pain control, we added to analgesic treatment adjunctive medications such as nonsteroidal anti-inflammatory drugs, paracetamol and metamizol. Multimodal analgesia, which combines analgesics from different classes and uses analgesic techniques that target different mechanisms of pain, is an effective method for postoperative pain relief $f^{5,7}$. In our study, regardless of the conditions of measurement, average pain intensity scores were below $1 / 10$ pts in all patients which justifies the appropriateness of using epidural anaesthesia. We obtained a better quality of analgesia than, for instance, Murphy et al. ${ }^{29}$ who used the para-vertebral route. Such good results were due, among others, to correct diagnosis of pain intensity made by the nurses and their high commitment to interventions aimed at relieving pain rated above $2 / 10$ pts. This is probably the reason why patients in our study reported significantly lower pain intensity than those after plastic surgery of the chest in the study conducted by Choudhry et al. ${ }^{30}$ where the patients were subjected to epidural anaesthesia with $0.2 \%$ ropivacaine and hydromorphone. In these patients, the therapeutic goal of pain relief was 4 or lower.

Good cooperation of doctors and nurses is one of the crucial components of proper pain control. In our department, only nurse anaesthetists ${ }^{31}$ modify analgesia within the scope of the doctor's order ${ }^{12}$. In the medical log, the doctor records the minimum and maximum analgesic dosage for each patient and a "rescue drug" to be given in case of breakthrough pain. Based on the result of the evaluation of pain and sedation as well as the guidelines available in the department, nurses may, for example, reduce or increase the flow rate of analgesic mixture administered by an epidural catheter and/or give a "rescue drug". This management shortens the time from the onset of pain until it is resolved. Twycross et al. ${ }^{32}$ points out that pain scores, even if recorded, not always guide the nurses' choice of postoperative pain-relieving interventions. Therefore, in order to prevent this wrong clinical practice, we supervise the proper implementation of analgesic guidelines.

In our study patients after thoracotomy felt more severe pain than those after plastic surgery of the chest. This probably resulted from the number of inserted chest drains (only 2 drains were installed in thoracotomy), the way they were set up and the duration of drainage. In patients after thoracotomy, air and fluid from the pleural 
cavity were evacuated through drain (s) introduced via an additional skin cut in the chest wall. On the other hand, in patients after correction of deformity of the anterior chest wall, a drain was led through the lower pole of the wound. The purpose of drainage in these patients was to remove serous-bloody fluid that accumulated in the retrosternal space and/or air if the pleural cavity was opened. In addition, in the case of thoracotomy, drains in the chest were generally kept longer (3-4 days) than after plastic surgery ( 2 days). Researchers point out that the factors associated with surgical trauma, such as the extent of operation, duration of trauma and the presence of drainage, are responsible for postoperative pain ${ }^{3}$.

Our study showed that the intensity of pain increased with age. Similar observations are made in the study conducted by Schnabel et al. ${ }^{4}$, who reported more severe pain in adolescents than in younger children. The authors noted that adolescents received a smaller number of additional analgesics. Therefore, due to the risk of insufficient analgesia, special attention should be paid to this group of patients.

Study limitations. The Participant, Care Provider, Investigator and Outcomes Assessor were not blinded for control or intervention conditions.

\section{Relevance to clinical practice}

The basis for effective pain relief in patients after thoracic surgery is the possibility of modifying analgesia by nurses within the scope of doctor's order based on the three-step pain assessment method. For this purpose, it is necessary for teams of doctors and nurses to develop uniform pain management guidelines, including evaluation, treatment and documentation of pain. It is also crucial to educate medical staff and patients and properly supervise the procedures.

\section{CONCLUSIONS}

The analgesic mixture of $0.125 \%$ bupivacaine and $5.0 \mu \mathrm{g} / \mathrm{mL}$ fentanyl given in the continuous infusion into the thoracic epidural space is as effective as the administration of $0.2 \%$ ropivacaine solution with $5.0 \mu \mathrm{g} / \mathrm{mL}$ fentanyl. The effectiveness of epidural analgesia depends on the number of pain measurements and the number of interventions undertaken by nurses to relieve pain.

Acknowledgement: This work was supported by the National Tuberculosis and Lung Diseases Research Institute, Poland [grant number 10.7].

Author contributions: LT: study design, statistical analysis, data interpretation and writing the draft of the article; DF: study design, collecting data, and critically revised the manuscript; DG, HK: data collection.

Conflict of interest statement: None declared.

\section{REFERENCES}

1. Kanagaratnam A, Phan S, Tchantchaleishvili V, Phan K. Ravitch versus Nuss procedure for pectus excavatum: systematic review and metaanalysis. Ann Cardiothorac Surg 2016;5:409-21.

2. Findik G, Gezer S, Sirmali M, Turut H, Aydogdu K, Tastepe I, Karaoglanoglu N, Kaya S. Thoracotomies in children. Pediatr Surg Int 2008;24:721-5.

3. Kolettas A, Lazaridis G, Baka S, Mpoukovinas I, Karavasilis V, Kioumis I, Pitsiou G, Papaiwannou A, Lampaki S, Karavergou A, Pataka A, Machairiotis N, Katsikogiannis N, Mpakas A, Tsakiridis K, Fassiadis $\mathrm{N}$, Zarogoulidis K, Zarogoulidis P. Postoperative pain management. J Thorac Dis 2015;7:S62-72.

4. Schnabel A, Thyssen NM, Goeters C, Zheng H, Zahn PK, Van Aken $\mathrm{H}$, Pogatzki-Zahn EM. Age- and procedure-specific differences of epidural analgesia in children-a database analysis. Pain Med 2015;16:544-53.

5. Misiolek H, Cettler M, Woron J, Wordliczek J, Dobrogowski J, Mayzner-Zawadzka E. The 2014 guidelines for post-operative pain management. Anaesthesiol Intensive Ther 2014;46:221-44.

6. Chou R, Gordon DB, de Leon-Casasola OA, Rosenberg JM, Bickler S, Brennan T, Carter T, Cassidy CL, Chittenden EH, Degenhardt E, Griffith S, Manworren R, McCarberg B, Montgomery R, Murphy J, Perkal MF, Suresh S, Sluka K, Strassels S, Thirlby R, Viscusi E, Walco GA, Warner L, Weisman SJ, Wu CL. Management of Postoperative Pain: A Clinical Practice Guideline From the American Pain Society, the American Society of Regional Anesthesia and Pain Medicine, and the American Society of Anesthesiologists' Committee on Regional Anesthesia, Executive Committee, and Administrative Council. J Pain 2016;17:131-57.

7. Glowacki D. Effective pain management and improvements in patients' outcomes and satisfaction. Crit Care Nurse 2015;35:33-43.

8. Baidya DK, Pawar DK, Dehran M, Gupta AK. Advancement of epidural catheter from lumbar to thoracic space in children: comparison between $18 \mathrm{G}$ and $23 \mathrm{G}$ catheters. J Anaesthesiol Clin Pharmacol 2012;28:21-7

9. Walaszczyk M, Knapik P, Misiołek H, Korlacki W. Epidural and opioid analgesia following the Nuss procedure. Med Sci Monit 2011;17:PH81-6.

10. Lejus C, Surbled M, Schwoerer D, Renaudin M, Guillaud C, Berard L, Pinaud M. Postoperative epidural analgesia with bupivacaine and fentanyl: hourly pain assessment in 348 paediatric cases. Paediatr Anaesth 2001;11:327-32.

11. Panni M, Segal S. New local anesthetics. Are they worth the cost? Anesthesiology Clin N Am 2003;21:19-38.

12. Tomaszek L, Tomalak W, Gajdosz R, Buchwald J. Intermittent thoracic epidural administration of bupivacaine-morphine versus intravenous infusion of morphine after thoracic surgery in children and adolescents. Anest Ratow 2015;9:260-8.

13. Association of Paediatric Anaesthetists of Great Britain and Ireland. Good practice in postoperative and procedural pain management 2nd Edition. Paediatr Anaesth 2012;22(Suppl1),1-79.

14. Baratta JL, Schwenk ES, Viscusi ER. Clinical consequences of inadequate pain relief: barriers to optimal pain management. Plast Reconstr Surg 2014;134:15S-21S.

15. Rabbitts JA, Zhou C, Groenewald CB, Durkin L, Palermo TM. Trajectories of postsurgical pain in children: risk factors and impact of late pain recovery on long-term health outcomes after major surgery. Pain 2015;156:2383-9.

16. Twycross A, Collis S. How well is acute pain in children managed? A snapshot in one English hospital. Pain Manag Nurs 2013;14:28.

17. Twycross A, Finley GA. Children's and parents' perceptions of postoperative pain management: a mixed methods study. J Clinl Nurs 2013;22:3095-108.

18. Guntinas-Lichius O, Volk GF, Geissler K, Komann M, Meissner W. Pain after paediatric otorhinolaryngologic surgery: a prospective multicentre trial. Eur Arch Otorhinolaryngol 2014;271:2049-60.

19. Kozlowski LJ, Kost-Byerly S, Colantuoni E, Thompson CB, Vasquenza KJ, Rothman SK, Billett C, White ED, Yaster M, Monitto CL. Pain prevalence, intensity, assessment and management in a hospitalized paediatric population. Pain Manag Nurs 2014;15:22-35.

20. Andersson V, Bergman S, Henoch I, Ene KW, Otterström-Rydberg $\mathrm{E}$, Simonsson $\mathrm{H}$, Ahlberga K. Pain and pain management in hos- 
pitalized patients before and after an intervention. Scand J Pain 2017;15:229.

21. Boric K, Dosenovic S, Jelicic Kadic A, Batinic M, Cavar M, Urlic M, Markovina N, Puljak L. Interventions for postoperative pain in children: An overview of systematic reviews. Paediatr Anaesth 2017;27:893-904.

22. Manworren RC, Stinson J. Paediatric pain measurement, assessment, and evaluation. Semin Pediatr Neurol 2016;23:189-200

23. Tomaszek L. Evaluation of the efficacy and safety of thoracic epidural analgesia in children after thoracic surgery [dissertation]. Krakow: Jagiellonian University Medical College; 2012.

24. Ratner $B$. The correlation coefficient: Its values range between $+1 /-1$, or do they? Journal of Targeting, Measurement and Analysis for Marketing 2009;17;139-42.

25. Yoo W, Mayberry R, Bae S, Sigh K, Peter HQ, Lillard JW. A study of effects of multicollinearity in the multivariable analysis. Int J of App Sci Technol 2014:4:9-19.

26. Murray L, Hien N, Lee YF, Remmenga MD, Smith DW. Variance inflation factors in regression models with dummy variables. Annual Conference on Applied Statistics in Agriculture 2012.http://newprairiepress.org/agstatconference/2012/proceedings/12Murray 2012.

27. Walaszczyk M, Wiench R, Copik M, Karpe J, Łowicka M, Pióro A, Knapik $\mathrm{P}$, Misiołek H. Ropivacaine has no advantage over bupivacaine in thoracic epidural analgesia for patients with pectus excavatum un- dergoing the Nuss procedure - a single blind randomized clinica trial comparing efficacy and safety. Kardiochir Torakochirurgia Pol 2018;15(1):5-9.

28. Macias A, Monedero P, Adame M, Torre W, Fidalgo I, Hidalgo F. A randomized, double-blinded comparison of thoracic epidural ropivacaine, ropivacaine/fentanyl, or bupivacaine/fentanyl for postthoracotomy analgesia. Anesth Analg 2002;95(5):1344-50.

29. Murphy T, McCheyne A, Karlsson J. Analgesic management after thoracotomy for decortication in children: a retrospective audit of 83 children managed with a paravertebral infusion-based regime. Paediatr Anaesth 2016;26:722-6.

30. Choudhry DK, Brenn BR, Sacks K, Reichard K. Continuous chest wall ropivacaine infusion for analgesia in children undergoing Nuss procedure: a comparison with thoracic epidural. Paediatr Anaesth 2016;26:582-9.

31. Kusza K, Kübler A, Maciejewski D, Owczuk R, Wujtewicz M, Piechota M. Guidelines of the Polish Society of Anaesthesiology and Intensive Therapy determining principles, conditions and administrative aspects of anaesthesiology and intensive therapy services. Anaesthesiol Intensive Ther 2012;44:177-87.

32. Twycross A, Forgeron P, Williams A. Paediatric nurses' postoperative pain management practices in hospital based non-critical care settings: a narrative review. Int J Nurs Stud 2015;52:836-63. 